\title{
Effects of Locally Delivered Morin Hydrate on lodoacetate- induced Temporomandibular Joint Osteoarthritis in Rats
}

Efeitos locais da indução de Hidrato de Morina na articulação temporomandibular de ratos com osteoartrite induzida por lodoacetato

Abdelrahman Mohamed Galal ABDELHAMEED ${ }^{1}$, Said Mahmoud Mohamed HANI ${ }^{1}$, Ahmed Mohamed Mohamed SOLIMAN ${ }^{1}$

1 - Al-Azhar University - Faculty of Dental Medicine - Boys - Oral and Dental Biology Department - Cairo - Egypt.

\begin{abstract}
Objectives: morin hydrate has been reported to possess many beneficial pharmacological potentialities including antioxidant and anti-osteoarthritic effects. The antiosteoarthritic properties of locally administrated morin have not been investigated. The objective of this study is to evaluate the locally delivered morin on the temporomandibular joint osteoarthritis in rat. Materials and methods: thirty young adult female Sprague Dawley rats were randomly arranged into three groups; control, osteoarthritis and osteoarthritis with morin. Both the iodoacetate for osteoarthritis induction and morin hydrate therapy were delivered unilaterally via intraarticular route. Results: morin reduced osteoarthritis manifestations with prominent thickening of both condylar fibrous layer and articular disc accompanied with discal cells hypertrophy that ultimately acquired chondrocytes features. The condylar cartilage matrix showed enhancement of extracellular matrix production with morin administration. Discussion: the present study has elucidated antiosteoarthritic effect of intraarticular injection of morin hydrate. Although morin has managed to prevent the propagation and advancing some of the recorded osteoarthritic manifestations; however, it showed some failure in managing others. The administration of morin hydrate modulated the structure of the joint rather than restore it back to its typical configuration. Conclusion: the morin hydrate administration to osteoarthritic animals showed relieve in some of osteoarthritic features and modulated the structure of some joint components to compensate the unhandled manifestations.
\end{abstract}

\section{KEYWORDS}

Iodoacetate; Morin; Osteoarthritis; OARSI score; Temporomandibular joint.

\section{RESUMO}

Objetivo: Relata-se que o Hidrato de Morina possui diversas potencialidades farmacológicas benéficas, incluindo efeitos antioxidantes e anti-osteoartríticos. As propriedades antiosteoartríticas da morina administrada localmente não foram investigadas. O objetivo deste estudo éavaliar a Morina administrada localmente sobre a osteoartrite da articulação temporomandibular em ratos. Material e métodos: Trinta ratos adultos jovens de linhagem Sprague Dawley foram dispostos aleatoriamente em três grupos: grupo controle, grupo com osteoartrite e grupo com osteoartrite e Morina. Tanto o Iodoacetato para a indução da osteoartrite como a terapia com Hidrato de Morina foram administrados unilateralmente por via intra-articular. Resultados: AMorina reduziu as manifestações da osteoartrite com espessamento proeminente tanto da camada fibrosa condilar como do disco articular acompanhado de hipertrofia das células discais que acabaram por adquirir características condrócitas. A matriz da cartilagem condilar mostrou um aumento da produção de matriz extracelular com administração de Morina. Discussão: O presente estudo elucidou o efeito antiosteoartrítico da injeção intra-articular de Hidrato de Morina. Apesar da Morina ter impedido a propagação e o avanço de algumas das manifestações osteoartríticas registadas, mostrou algumas falhas na manipulação de outras. A administração de Hidrato de Morina modulou a estrutura da articulação em vez de restaurar à sua configuração típica. Conclusão: A administração de Hidrato de Morina em animais osteoartríticos mostrou alívio em algumas das características osteoartríticas e modulou a estrutura de alguns componentes da articulação em compensação às manifestações não tratadas.

\section{PALAVRAS-CHAVE}

Iodoacetato; Morina, Osteoartrite; Escore OARSI; Articulação temporomandibular. 


\section{INTRODUCTION}

T he temporomandibular joint osteoarthritis (TMJOA) is significantly serious category of the temporomandibular joint disorders in the oral and maxillofacial region, which can lead to severe joint pain and movement disorder and seriously damage the life quality of the patient. Despite its name, osteoarthritis (OA), it cannot be considered as an inflammatory disease, but rather a degenerative disorder initiating at the articular cartilage. The TMJOA is a common disorder among the population, that is more prevalent in females than in males, and increases in prevalence with age [1]. The TMJOA may be unilateral or bilateral and its strong preference for women may be due to estrogen receptor a polymorphism and may be associated with increased pain susceptibility in female TMJOA patients [2].

Excessive mechanical loading on normal articular cartilage or normal mechanical loading on impaired articular cartilage is generally speculated to initiate the disruption of cartilage matrix homeostasis, resulting in OA [3]. Overloading on the TMJ, including severe malocclusion, skeletal jaw asymmetry, and muscle overuse, could be considered as the main causative factors for TMJOA induction $[4,5]$.

The majority of TMJOA is difficult to attribute to overload, so that, the causes of impaired condylar cartilage in the TMJ remain obscure [6]. Patients with TMJOA usually have pain and dysfunction of TMJ with reduced quality of life. The treatment of TMJOA was directed toward relieving pain, decelerating the progress of the disease, and restoring TMJ function.

The animal models of TMJOA may be critical approach to investigate the pathogenesis of TMJOA and to evaluate the potential of therapeutic interventions because obtaining clinical samples from patients with TMJOA is difficult if impossible. The animal models of OA were approached via different procedures; including surgical and chemical methods with the least invasive among the animal models of
OA was the chemical one. The most commonly used compound in OA induction today is sodium monoiodoacetate (MIA), which inhibits the glyceraldehyde-3-phosphate dehydrogenase of the Krebs cycle leading to the death of chondrocytes [7-10]. The MIA-induced OA model reproduces cartilage lesions with loss of proteoglycan matrix and functional joint impairment similar to human OA, as well as, chondrocyte necrosis, cell cloning (chondrones), fibrillation, and erosion with exposure of subchondral bone [11].

Morin, 3,5,7,2',4'-pentahydroxyflavone, is a flavonoid isolated as a yellow crystalline polyphenolic pigment derived from plants belonging to the Moraceae family. Morin is one of the principal constituents of many preparations of botanical origin and is recommended by traditional medicine to treat several human pathologies [12]. Previous studies have demonstrated that morin has various pharmacological activities, including antiinflammatory, antioxidant, anti-angiogenic, and anticancer effects [13]. In previous study, the pretreatment with $50 \mathrm{mmol} / \mathrm{L}$ morin resulted in a significantly reduced expression level of MMP-3 and MMP-13 in IL- $1 \beta$-induced OA at chondrocytes. Morin also induced the expression of tissue inhibitor of metalloproteinase (TIMP)-1 without causing cytotoxicity. Since tissue inhibitors of matrix metalloproteinases (TIMMPs) are the endogenous inhibitors of matrix metalloproteinases (MMPs), it was speculated that morin might modulate the balance between MMP and TIMMP expression to exert its antiarthritic effects in IL-1 $\beta$-treated rat articular chondrocytes [14].

Vascular endothelial growth factor (VEGF) is known to play a major role in angiogenesis, though its role in OA pathogenesis and progression has been revealed previously [15]. The upregulated VEGF, during OA pathogenesis, has been shown to stimulate MMPs production in chondrocytes, so that the expression of VEGF in chondrocytes could be a parameter for OA severity in the present study. The OA Research Society International (OARSI) introduced the 
OARSI Osteoarthritis Cartilage Histopathology Assessment System (OOCHAS). The OARSI scoring system assesses cartilage pathogenesis by measuring both the vertical (grade) and horizontal (stage) progression of OA cartilage manifestations. The overall score is defined as the combined OA grade $0-6$ points and OA stage 0-4 points, representing a combined assessment of OA severity and extent 0-24 points [16].

\section{MATERIALS AND METHODS}

This study was carried out on 30 young adult $(180 \pm 50 \mathrm{~g})$ female Sprague Dawley rats and conducted in the animal research unit, Cairo University, Cairo, Egypt. According to the Ethical Research Committee Protocol of the faculty of Dental Medicine, Al-Azhar University, Cairo, Egypt. The procedures were conducted in accordance with Committee for the Purpose of Control and Supervision on Experiments on Animals (CPCSEA Guidelines).

The animals were divided randomly into three main groups as follows: Group (I): 10 rats represented the negative control group for the osteoarthritic group (G II). Group (II): 10 rats were subjected to osteoarthritis induction with intra-articular injection of 1 mg sodium monoiodoacetate (MIA; Sigma, St. Louis, MO, USA). The temporomandibular joint osteoarthritis (TMJOA) induction was committed by a single dose of $1 \mathrm{mg}$ Sodium monoiodoacetate (MIA; Sigma, St. Louis, MO, USA) dissolved in $50 \mu \mathrm{L}$ of distilled water unilaterally in rats in the right side via intraarticular route into the upper joint compartment [17]. Then the animals of this group were sacrificed after one week of OA induction by decapitation for recording the various osteoarthritic manifestations in TMJ. Group (III): 10 rats were treated, after osteoarthritis induction, with a single dose of $40 \mathrm{mg} / \mathrm{kg}$ body weight of morin hydrate (Morin hydrate; Sigma, St. Louis, MO, USA) [18], dissolved in $50 \mu \mathrm{L}$ of distilled water via intra-articular route in the right side. The animals were sacrificed, four weeks after morin administration.
After the end of the experimental period, the rats were sacrificed by decapitation. In all groups, the skull was cut into two halves through the sagittal plane and the experimental right side was soaked for $72 \mathrm{~h}$ in $10 \%$ neutral buffered formalin for fixation. The hemicrania were demineralized by $14 \%$ ethylene diamine tetraacetic acid (EDTA) at pH 7.1 for 3 weeks until the tissue specimens became fully decalcified. The specimens were paraffin embedded, and the paraffin embedded TMJ blocs were sagittally cut in serial sections at a 5-7 $\mu \mathrm{m}$ thickness, so that the tissue sections were cut in a direction parallel to the lateral surface of the mandibular ramus. The tissue sections of TMJ in all groups of animals were microtechnically processed for the following evaluations:

(1) Histological investigations: comprising; hematoxylin and eosin (H \& E) stain, and Toluidine Blue (TB) stain in order to survey (a) structural changes induced by the different injected materials and (b) perform OA score in the various experimental groups according to OARSI scoring system. The OA scoring: was estimated according to two parameters including the grade and stage scale made by Pritzker KPH, et al 2006 [16]. The final score was defined by the assessment of combined OA grade and OA stage.

(2) Histochemical investigations: including : alcian blue (AB) $\mathrm{pH} 2.5$ reaction, as well as alcian blue- Periodic acid Schiff reaction (AB-PAS) to record the changes in the different types of glycoproteins and proteoglycans content in the TMJ cartilage matrices in the different experimental groups with the control group. Immunohistochemical reaction (IHC), where the sections were examined under light microscopy for localization of VEGF within the articular cartilage via section treatment with rabbit polyclonal antibodies against VEGF-A (Lab Vision; Fremont, CA, USA) via peroxidase technique.

The data were recorded, and statistically analyzed. The P-values were given for comparison of the mean difference between the control group and the experimental groups using the independent sample $t$ test. One-way 
analysis of variance (ANOVA) test was used for comparison between the different groups.

\section{RESULTS}

\section{Control group (G I)}

Histologically: the joint components showed intact and typical configuration that was represented in the OARSI score denoting absence of OA manifestations (Figure 1). The mandibular condyle was composed of typical structure from the articular surface inward; including the condylar fibrous layer, condylar proliferative layer, condylar cartilage layer and condylar subarticular bone containing large bone marrow spaces with interlacing numerous bone trabeculae. The roof of glenoid fossa was lined with fibrous tissue layer composed of densely arranged collagen fibers overlaying compact bone containing few, oval bone marrow spaces with some few bone marrow tissues.

The articular disc was composed of dense collagenous fibrous tissue containing densely arranged coarse collagen bundles with some interspersed flattened fibroblast. The synovium was composed of; cellular intima with one to four layers of synovial cells embedded into fiber free matrix and vascular subintima composed of loose connective tissue layer containing variably sized vascular elements (Figure 2 and 3). The toluidine blue stain revealed intense metachromatic stain through the matrix of the condylar fibrous, proliferative, and cartilaginous layers (Figure 4).

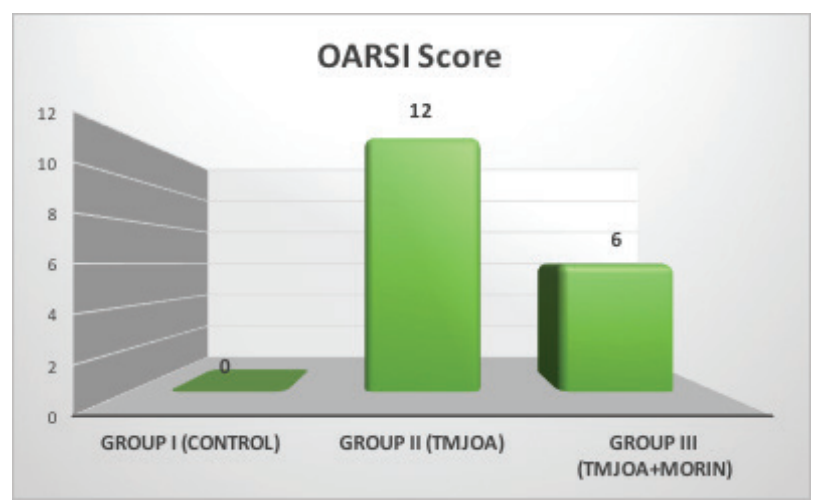

Figure 1 - the change in osteoarthritic score among the different experimental groups according to OARSI scoring system (Pritzker KP et al, 2006).

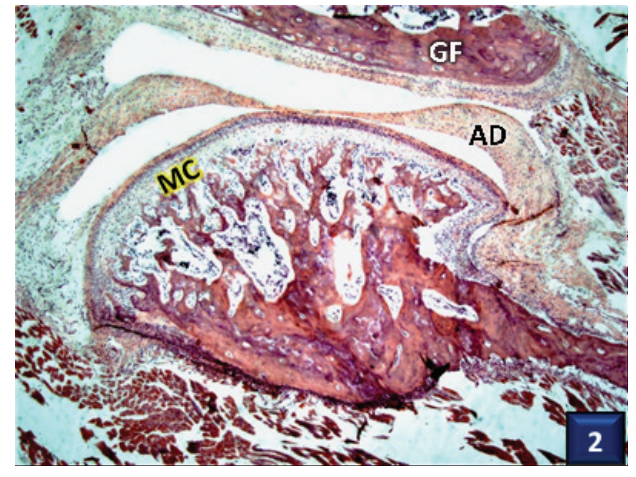

Figure 2 - the main histological structural components of TMJ and their positional relations to each other (H\& E stain, Mag. $X$ 40 ), articular disc (AD), mandibular condyle (MC), glenoid fossa (GF).

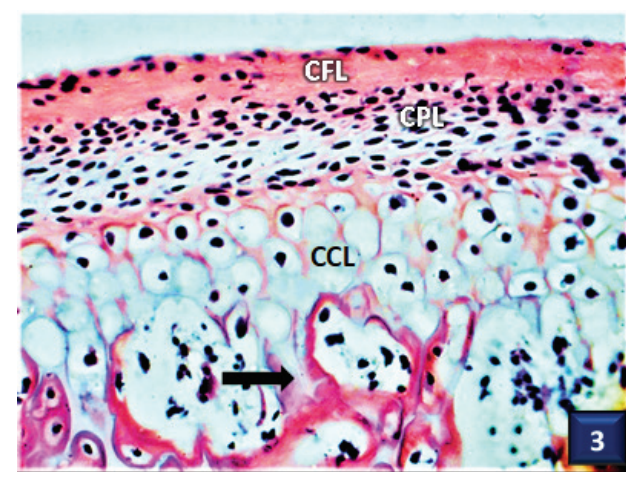

Figure 3 - the different layers of condylar cartilage including condylar fibrous layer (CFL), condylar proliferative layer $(\mathrm{CPL})$ and condylar cartilaginous layer (CCL). The deeper chondrocytes appear degenerated leaving wide lacunae below hypertrophic cartilage layer leaving large spaces separated by cartilage septae (arrow) in preparation for endochondral ossification (H \& E stain, mag. X400).

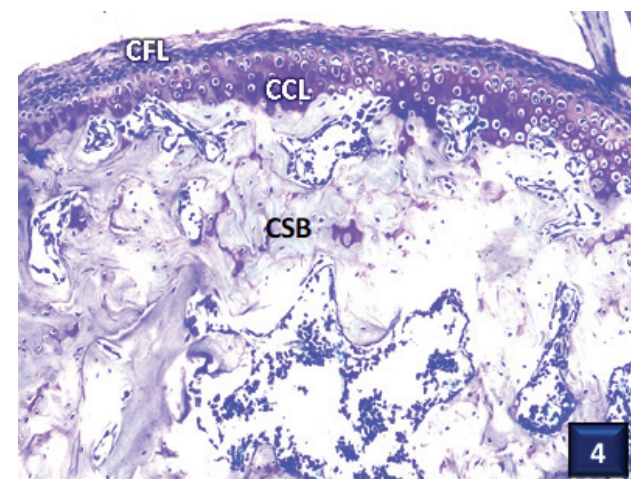

Figure 4 - articular fibrous layer (CFL), and condylar cartilage layer (CCL) appear intensely stained specially at the cartilage matrix and in the rims around chondrocytes. (TB reaction. Mag. X 100) (CSB: condylar subarticular bone). 
Histochemically; intense alcianophilic reaction throughout the matrix of condylar transitional layer and condylar hypertrophic layer was prominent (Figure 5). The AB-PAS reaction demonstrated intense periodate reaction throughout the matrix of condylar fibrous layer and condylar subarticular bone, while condylar cartilage layer showed intense alcianophilic reaction (Figure 6). Immunohistochemically; the IHC reaction showed negative immunoreaction to VEGF in most condylar cartilage cells with scanty cells revealed weak immunoreaction (Figure 7).

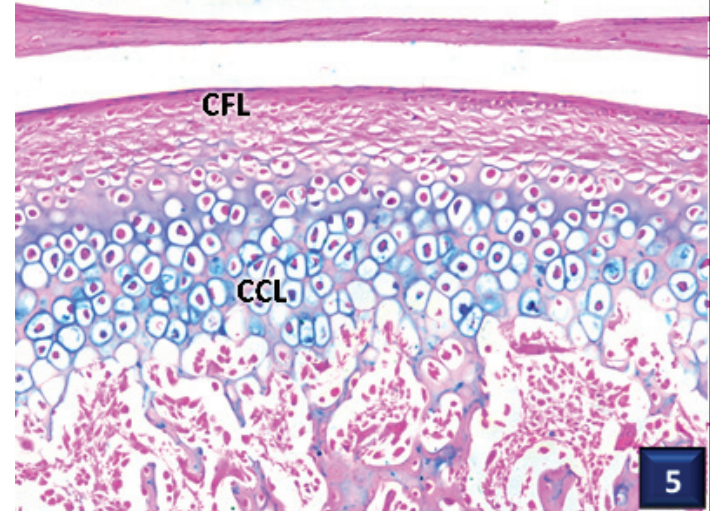

Figure 5 - moderate alcianophilic reaction throughout the matrix in the condylar hypertrophic cartilaginous layer (CCL) with more intense reaction in the perilacunar rim around chondrocytes. (AB pH2.5 reaction with nuclear fast red counterstain. Mag. X 200) (CFL: condylar fibrous layer).

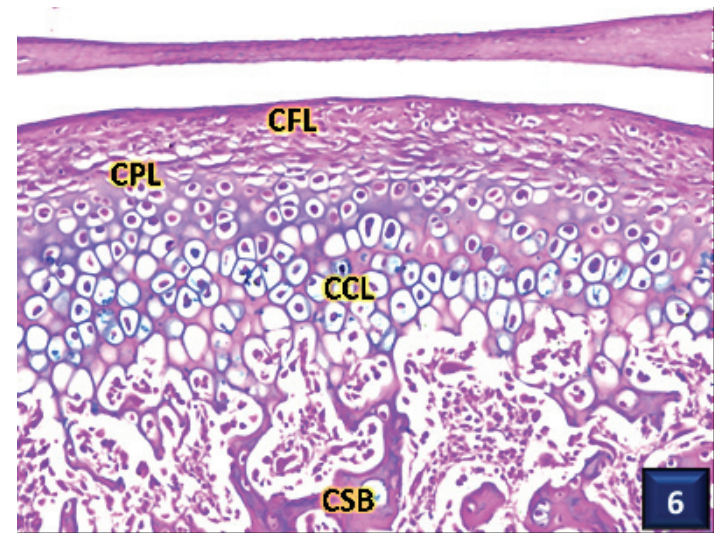

Figure 6 - intense periodate reaction in condylar fibrous layer (CFL), throughout the matrix of condylar cartilage (CCL) and in the perilacunar rim around chondrocytes. (AB-PAS reaction with hematoxylin counterstain. Mag. X 200) (CPL: condylar proliferative layer; CSB: condylar subarticular bone).

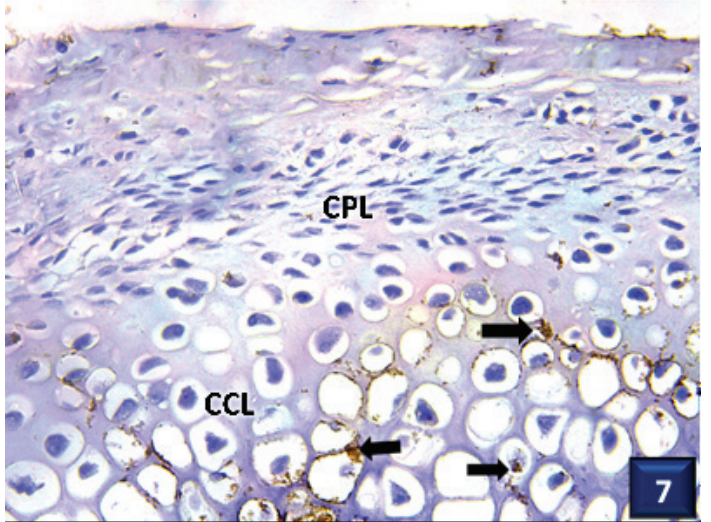

Figure 7 - negative VEGF immunoreactivity in most condylar cartilage cells but slight brown reactivity in some cells of the innermost cartilaginous layers (arrows). (VEGF immunostaining with hematoxylin counterstain. Mag. X 400) (CPL: condylar proliferative layer).

\section{The effects of MIA-induced osteoarthritis on TMJ (G II)}

Histologically: The mandibular condyle demonstrated thinning and uneven thickness of both the condylar fibrous and cartilaginous layers. The mandibular condyle showed marked collapse of the condylar cartilage layer with the development of edematous areas between and in the condylar layers. The chondrocytes underwent haphazard arrangement, variable shape and nuclear stain with degeneration of some cells while others showed proliferation and aggregation in clusters. The condylar subarticular bone became sclerotic with variable degrees, while the bone marrow was replaced with fibrous tissue and edematous areas. The articular disc suffered from severe thinning of its central part, while the peripheral parts demonstrated fraying of its constituting fibers with interfibrillar edema formation (Figs. 8 and 9). The TB stain revealed absence of metachromatic stain throughout the matrix of all layers of mandibular condyle except small widely spaced cartilage islands that showed moderate metachromatic stain (Figure 10). The OARSI score was12 that is the highest among the studied groups (Figure 1). 


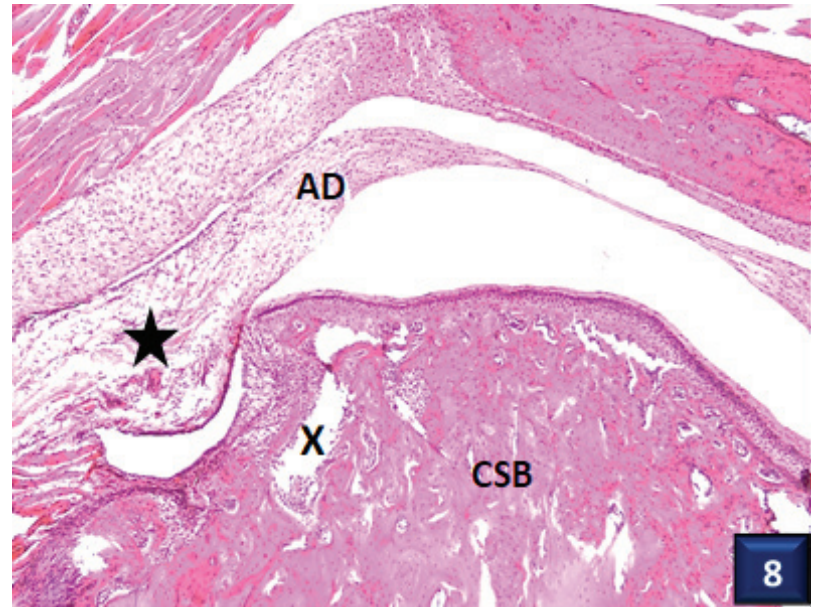

Figure 8 - the anterior zone of TMJ showing localized hypertrophy of the articular disc (AD) with interfibrillar edema particularly at its attachment with articular capsule (star). The condylar cartilage shows multiple cracks filled with edema fluid $(\mathrm{X})$ while most of subcortical bone (CSB) appears sclerotic with disappearance of most of bone marrow (H \& E stain, mag. X 100).

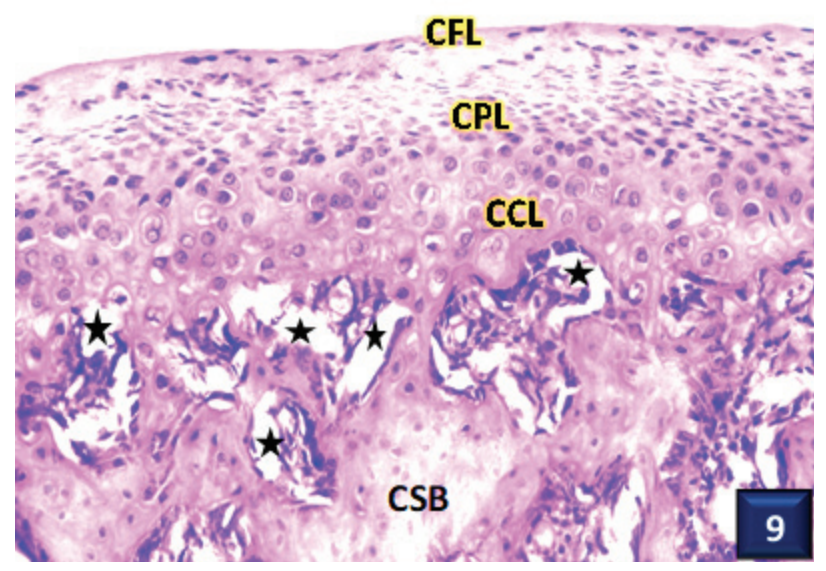

Figure 9 - irregular cell arrangement and morphology at condylar fibrous layer (CFL), condylar proliferative layer (CPL) and condylar cartilaginous layer (CCL) with atypical nuclear cytoplasmic ratio of chondrocytes. Chondrocytes appear mononuclear with hyperchromatism and variable nuclear shape, size and stain. The condylar subarticular bone (CSB) appears sclerotic enclosing empty spaces or clefts (stars). (H \& E stain, mag. X 200).

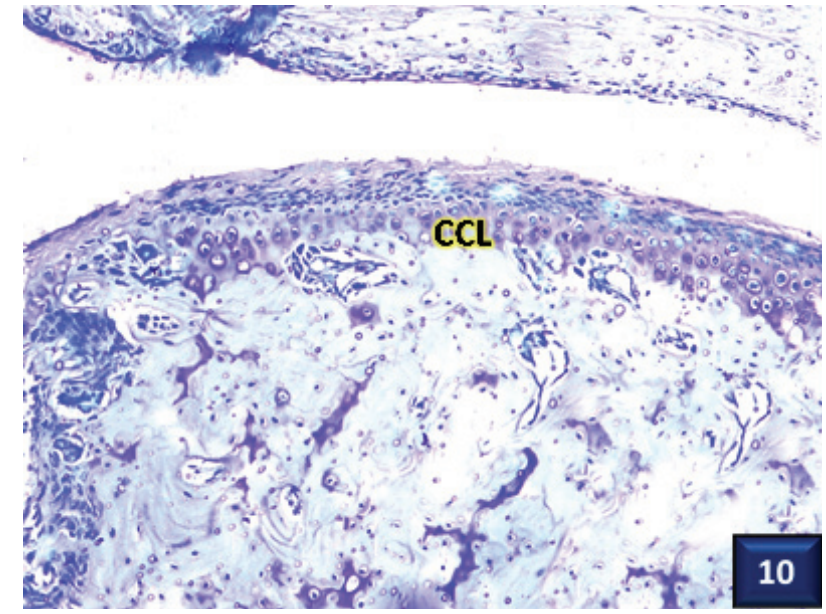

Figure 10 - the condylar cartilaginous layer (CCL) appears atrophic with moderately stained matrix. (TB stain. Mag. X 100).

Histochemically: the $\mathrm{AB}$ reaction showed negative alcianophilic material in the matrix of condylar fibrous layer and superficial part of condylar cartilaginous layer, but moderate reaction in the deep part of condylar cartilage (Figure 11). Moderate periodate material was found in the collapsed condylar cartilage layer by AB-PAS reaction, but such reaction was intense in both the condylar fibrous layer and the condylar subarticular bone (Figure 12). The immunohistochemical reaction: demonstrated intense and widely distributed VEGF positive material in the cells of condylar cartilage layer but weak reaction in the condylar fibrous layer (Figure 13).

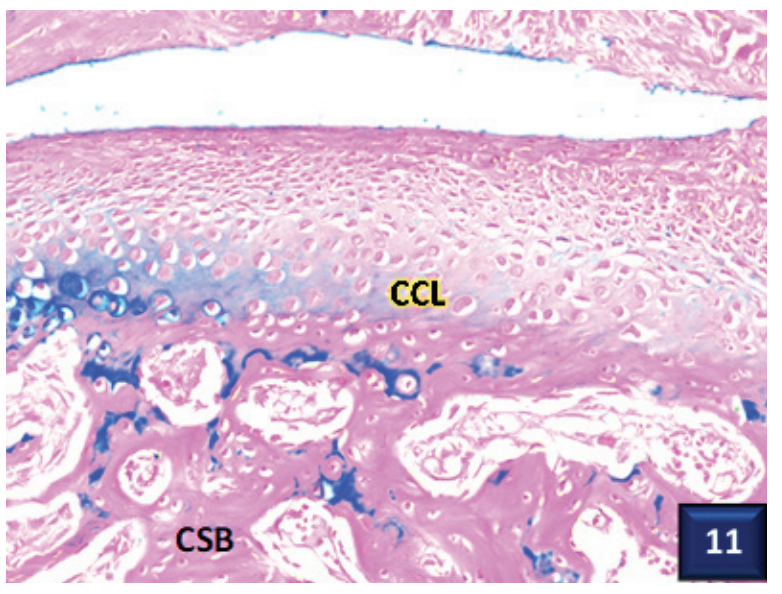

Figure 11 - absent alcianophilic reaction except intense scattered reactions in the deep part of condylar cartilaginous layer (CCL) and in condylar subarticular bone (CSB). (AB pH2.5 reaction with nuclear fast red counterstain. Mag. X 200). 


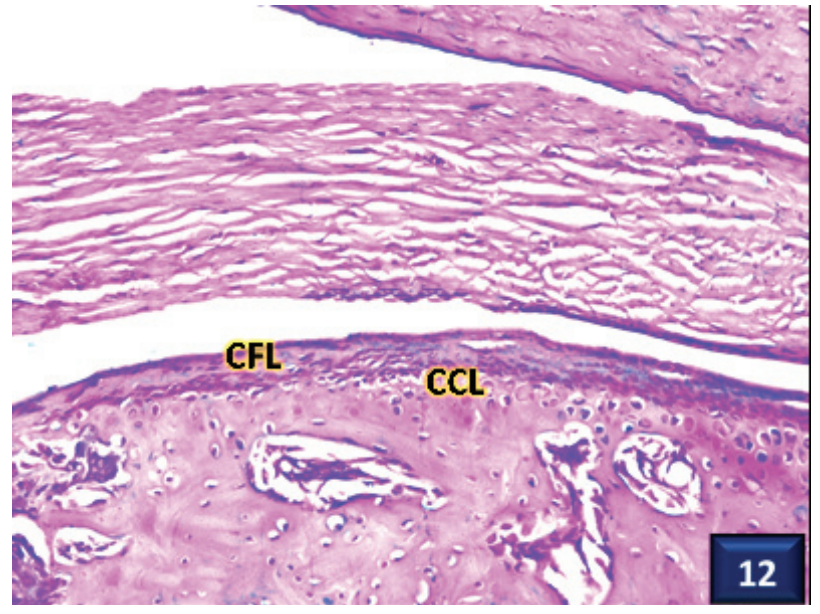

Figure 12 - moderate periodate reaction in the matrix of collapsed condylar cartilaginous layer (CCL) and in the friable articular disc but intense periodate reaction appears in the condylar fibrous layer (CFL). (AB - PAS reaction with hematoxylin counterstain. Mag. X 200).

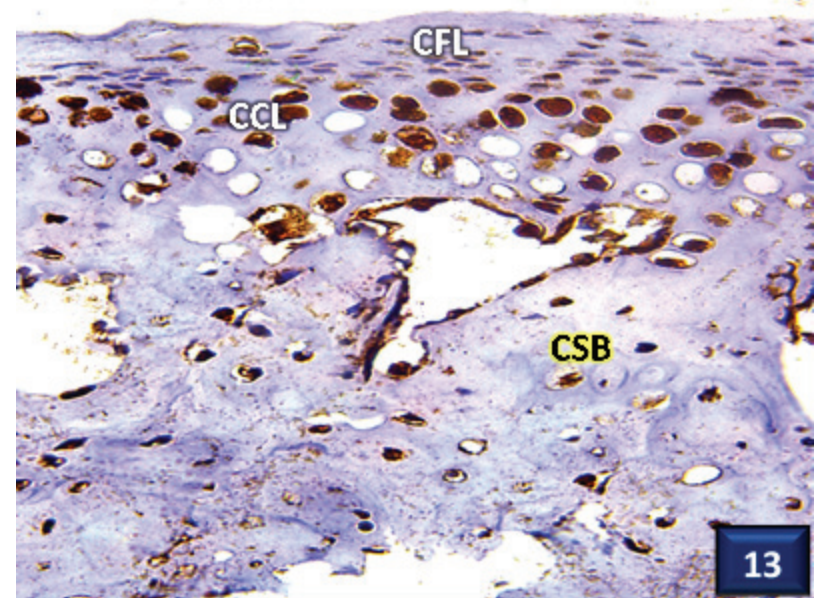

Figure 13 - high immunoreaction in both intensity and distribution in most of the superficial chondrocytes of condylar cartilaginous layer (CCL) but weak reaction in cells of condylar fibrous layer (CFL) and little reaction in osteocytes of condylar subarticular bone (CSB). (VEGF immunostaining with hematoxylin counterstain. Mag. X 400).

\section{The effects of morin hydrate on MIA- induced TMJOA (G III)}

Histologically: the administration of morin hydrate modulated variably the progression of osteoarthritic manifestations. Although some of the osteoarthritic features recorded in the osteoarthritic group were disappeared, some other osteoarthritic features did not. The animals demonstrated uneven thickening of both the condylar fibrous layer and condylar cartilage layer. The condylar cartilage regained partially its normal configuration and cellular arrangement. The condylar subarticular bone showed mild or even absence of sclerosis and the superficial bone marrow appeared fibrotic, while other marrow spaces showed normal hemopoeitic tissue. The articular disc was markedly thickened and demonstrated hypertrophy of discal cells that got chondrocytes like appearance (Figs. 14 and 15). The TB stain findings showed intense metachromatic stain in the matrix of condylar cartilaginous layer with occasional lightning or absence in its superficial zone (Figure 16). These findings were mirrored in the OARSI score, which recorded a lower level than that recorded in G II (Figure 1).

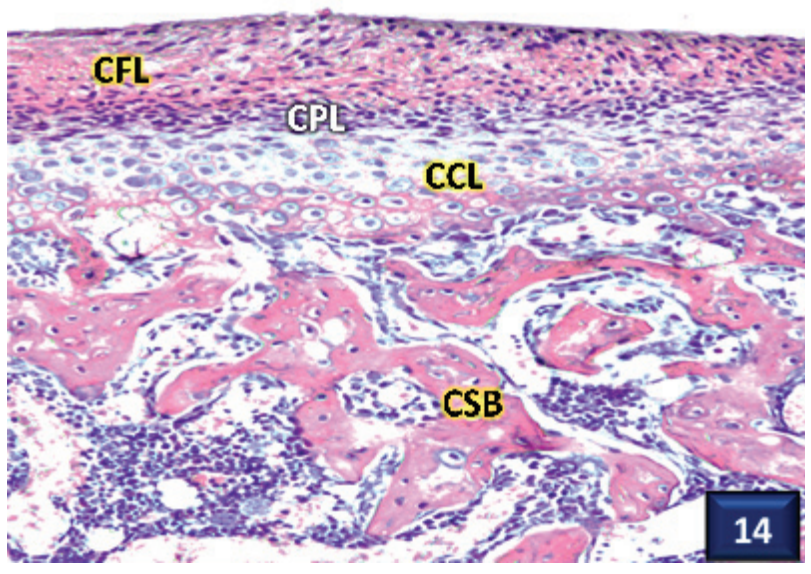

Figure 14 - indefinite condylar fibrous layer (CFL) and condylar proliferative layer (CPL) and condylar cartilage layer (CCL). The condylar subarticular bone (CSB) appears with almost normal structure and bone marrow spaces contain their regular bone marrow content. (H \& E stain, mag. X 200). 

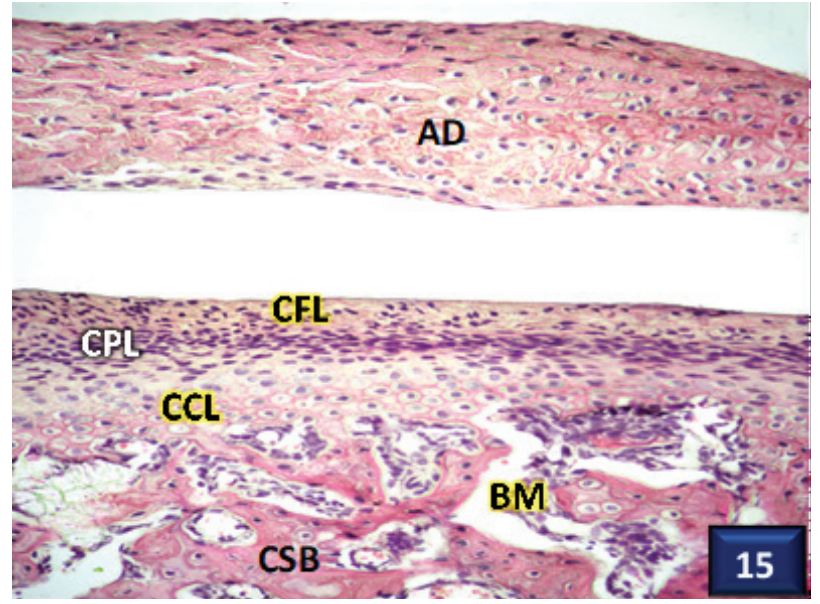

Figure 15 - uneven cell density of condylar fibrous layer (CFL) and condylar proliferative layer (CPL) with regional absence of condylar cartilaginous layer (CCL). The condylar subarticular bone (CSB) appears with some bone marrow (BM) spaces containing fibrous tissue. The articular disc (AD) appears thickened with some small interfibrillar edematous spaces, and some discal cells simulating chondrocytes. (H \& E stain, mag. X 200).

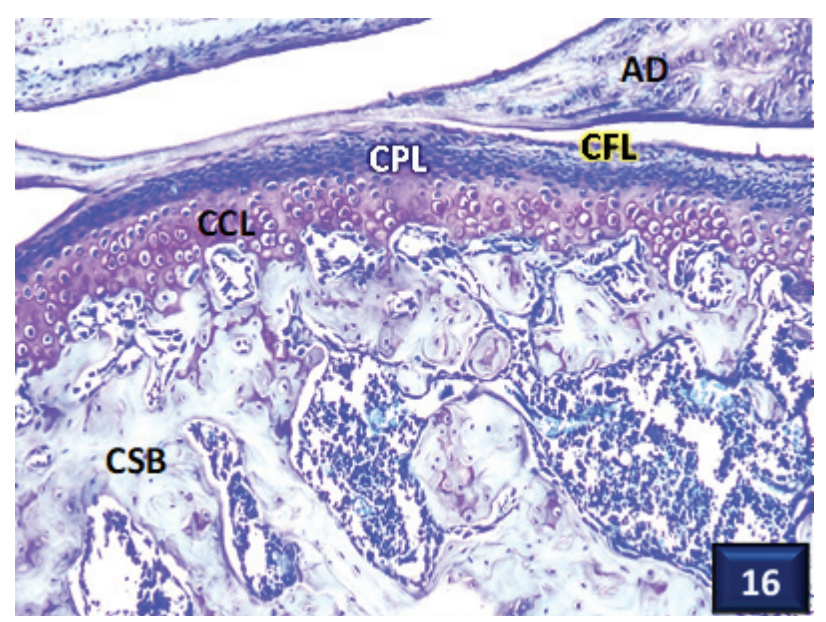

Figure 16 - moderate metachromatic stain in the condylar cartilage layer (CCL) but weak metachromatic stain in the condylar fibrous layer (CFL) and intense stain in condylar proliferative layer (CPL). The articular disc (AD) shows weak metachromatic stain in its matrix. (T.B. stain. Mag. X 100) (CSB: condylar subarticular bone).

Histochemically: the $\mathrm{AB}$ reaction demonstrated intense alcianophilic material in the matrix of condylar cartilaginous layer, but it was less distributed in the condylar fibrous layer (Figure 17), while the AB-PAS reaction showed moderate to intense periodate reaction in the cells of the condylar proliferative layer and moderate reaction in the matrix of the deeper layer (Figure 18). The immunohistochemical reaction: demonstrated profuse positive VEGF material in chondrocytes of condylar cartilage layer but less material in the cells of both the condylar fibrous layer and condylar proliferative layer (Figure 19).

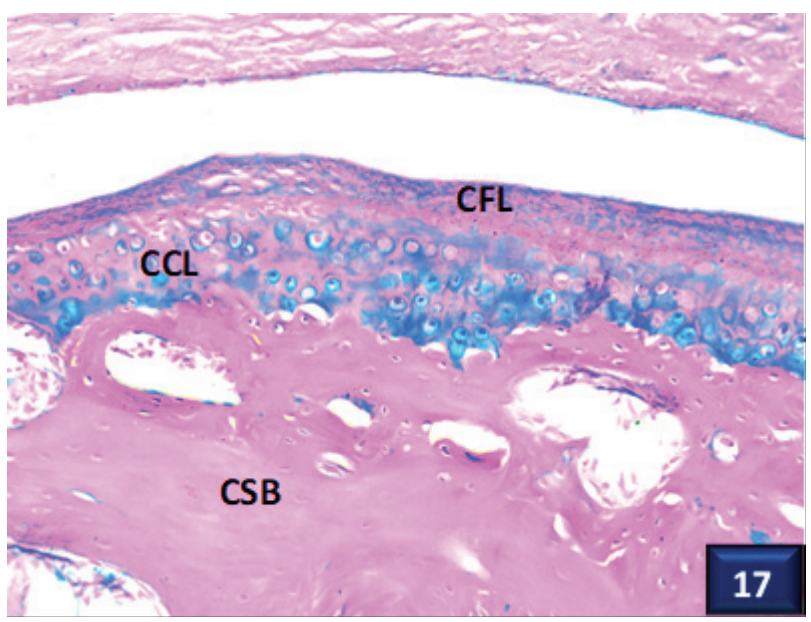

Figure 17 - intermittent intense alcianophilic reaction through the matrix of condylar cartilaginous layer (CCL). (AB pH2.5 reaction with nuclear fast red counterstain. Mag. X 200) (CFL: condylar fibrous layer; CSB: condylar subarticular bone).

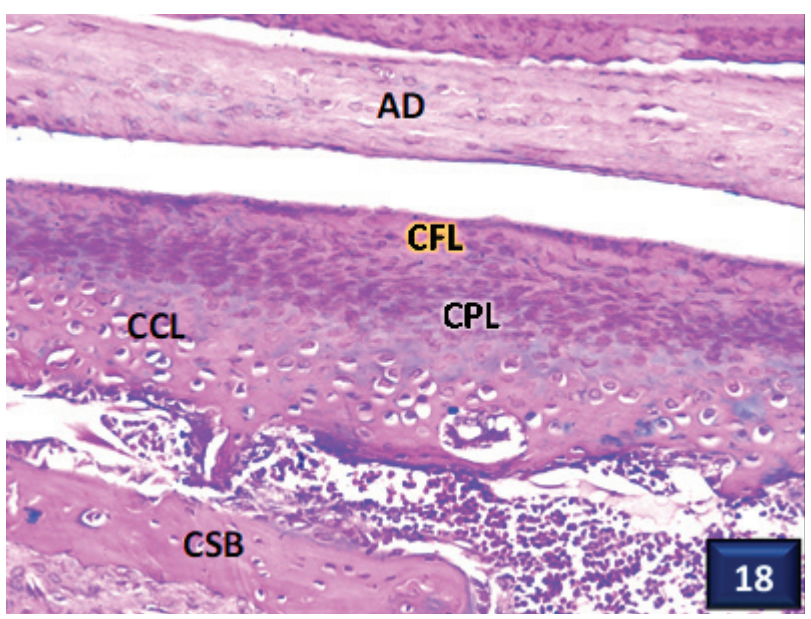

Figure 18 - the condylar fibrous layer (CFL), condylar proliferative layer (CPL), condylar cartilaginous layer (CCL) and condylar subarticular bone (CSB) reveal moderate periodate reaction but lighter reaction appears in the articular disc (AD). (AB-PAS reaction with hematoxylin counterstain. Mag. X 200). 


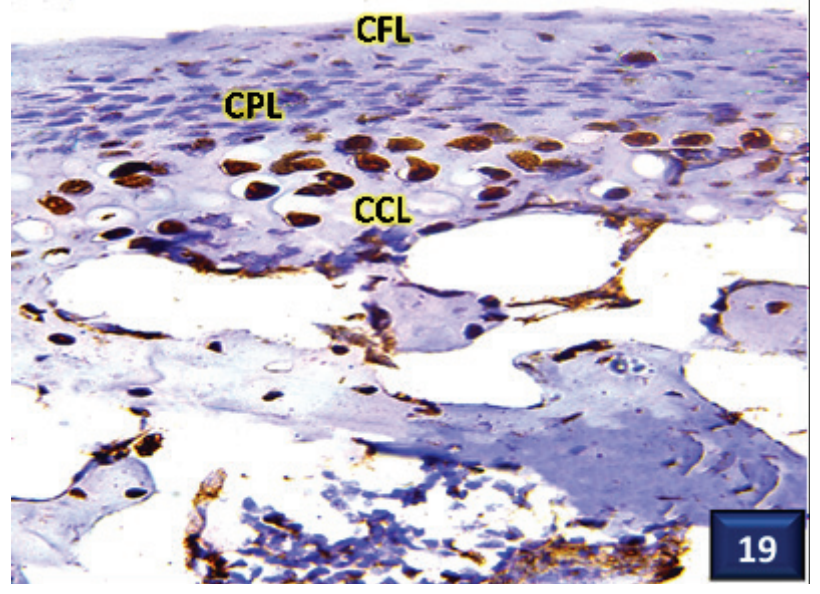

Figure 19 - intense immunoreaction in most chondrocytes of condylar cartilage layer (CCL), while the cells of condylar fibrous layer (CFL) and condylar proliferative layer (CPL) show almost no immunoreaction. (VEGF immunostaining with hematoxylin counterstain. Mag. X 400).

\section{DISCUSSION}

Despite its name, the osteoarthritis (OA) is generally accepted as a noninflammatory disease of the joints but rather a degenerative one essentially simulating an accentuation of the normal aging process of the articular cartilage [19]. They also indicated that the OA etiology is actually unknown, but the genetic and metabolic factors may be involved, and though it is a disease of later life, however, it can affect the traumatized joints in younger individuals. Many evidences indicated that TMJOA showed a high female to male preponderance, nearly $2: 1[1,2,20]$, and it primarily affects females after puberty and during the reproductive years. Such evidences had significantly directed the current study to be conducted on female animals rather than males in order to simulate its sex preponderance in the human model of the disease.

The MIA-induced TMJOA demonstrated condylar chondrocytes degeneration and apoptosis in the present study. This finding was concomitant with the previous investigations which revealed chondrocytes apoptosis as early as one day after MIA injection and this apoptosis reach its peak at the third day leading to hypocellularity in both the condylar cartilage and disc. The chondrocytes apoptosis in the early stages could be an important initiator of cartilage degeneration in the subsequent stages, a fact that was concluded by previous investigation [17]. The progressive loss of chondrocytes has led to changes in the histological and morphological features of the articular cartilage, ultimately resulting in changes that closely mimics the conditions seen in human OA. This affection on the chondrocytes by MIA have led to a failure of the persisting chondrocytes to maintain the normal homeostasis between synthesis and degradation of cartilage extracellular matrix components.

This imbalance between the anabolic and catabolic processes of the extracellular matrix is the presumed mechanism for the establishment of osteoarthritis presumed in the previous investigations [21]. The prominent influence of condylar cartilage in the present study was represented histochemically by the reduction in the expression of proteoglycans and glycoproteins throughout the condylar cartilage cells and matrix. The present histochemical findings are coincident with the findings noted in the previous investigation, which reported a loss of cartilage proteoglycans induced by the injection of MIA. This loss has been related to the increased activity of collagenase and gelatinase enzymes and the elevated amounts of both matrix metalloproteinases (MMP) and aggrecanase proteoglycan in the cartilage of rat post MIA injection [22].

The histological alterations associated with the MIA-induced TMJOA in the present study including the reduction in or even absence of proliferative layer of mandibular condyle, may interpret and lie behind the degenerative alterations in the various layers of mandibular condyle. Also, these observations may indicate the possibility of a disturbance in the metabolic activities due to defect in the nutritional supply to the joint. This disturbance was reflected with the inability of the proliferative layer to compensate and repair the loss in homeostasis of destructionrepair in cartilage reproduction. This ultimately led to failure of restoration of the normal chondrogenic activity comparable to cartilage loss in mandibular condyle. 
The immunohistochemical investigations in the present work demonstrated intense expression of the vascular endothelial growth factor (VEGF) in most chondrocytes in the cartilaginous layer of condyle. This finding may reflect the direct relation between osteoarthritis pathogenesis and the expression of VEGF in the condylar chondrocytes. The role of VEGF in osteoarthritis pathogenesis was reported in a previous investigation, which indicated that, VEGF was upregulated in the chondrocytes of mandibular condyles with osteoarthritic changes. They furtherly indicated that the VEGF binds to its receptor (VEGFR-2), leading to extracellular signal-regulated kinase (ERK1/2) activation. The ERK activation, helped the induction of matrix metalloproteinase (MMP), which aid in the degradation of the extracellular matrix during both the initiation and progression of TMJOA [23]. These previously reported mechanisms concerning the implement of VEGF in the pathogenesis of OA, could elucidate the significance of elevated VEGF expression in the chondrocytes of osteoarthritic mandibular condyle in the present investigation.

The present investigation has a pioneering step in evaluating the local administration of morin via the intraarticular injection of morin hydrate rather than the systemic route. The morin hydrate in the present study was intended to relieve the osteoarthritic manifestations, however, the findings have indicated that morin hydrate did not restore the joint structure adequately to its normal architecture, but it has evoked some modulations in the joint structure. The OA progression is time dependent and selective process, so that, after the treatment period, some osteoarthritic manifestations have been progressed while others were arrested by morin administration. The most interesting findings in the morin group were the occasional marked thickening of the condylar fibrous layer and the moderate thickening of the condylar cartilage layer.

The in vitro studies on the rat chondrocytes, have demonstrated that morin is able to inhibit the matrix metalloproteinases (MMPs) release induced by IL- $1 \beta$ stimulation, thereby preventing the breakdown of the cartilage matrix [24]. Concerning the MMPs as a suggested mediator in the pathogenesis of OA, the previous observations were concomitant with the histochemical findings that unveiled the relative enhanced ability of chondrocytes in the various matrix components production including; proteoglycans and glycoproteins. The expression of VEGF in the present study was reduced in the morin administrated group in relation to that recorded in the osteoarthritis group. However, the antiVEGF potential of morin was relatively low in the present investigation compared to that recorded in the previous studies that have used morin hydrate, a condition which may be attributed to the difference in the route of administration.

The occasional marked thickening of articular disc and the condylar fibrous layer in some animals may simulate a compensatory reaction to the decreased thickness of condylar cartilage layer in order to reduce the forces on the condylar subarticular bone. This compensatory reaction may be furtherly reflected on the condylar subarticular bone, as it showed prominent decrease in the degree of sclerosis. Taken together, the locally delivered morin hydrate relatively relief the progression of TMJOA that was represented in the OARSI score, however, it didn't restore the joint back to normal.

\section{CONCLUSION}

The intra-articular injection of sodium monoiodoacetate (MIA) could induced temporomandibular joint osteoarthritis, which may simulate that of human indicating the ideality of the rat as an animal model for the demonstration of OA. The osteoarthritic group showed many degenerative features rather than inflammatory ones, this is compatible with the consideration of $\mathrm{OA}$ as a degenerative disorder. The morin hydrate administration to osteoarthritic animals showed relieve in some of the osteoarthritic features and have modulated the structure of some joint components, such modulation may be regarded as a compensatory response to cope with the persisting osteoarthritic manifestations. 
The deterioration of condylar cartilage and failure of the proliferative layer of mandibular condyle to compensate for and efficiently and properly match the need for condylar repair induction, may lay behind and explain the absence the absence of cartilaginous layer with subsequent cortification of condylar surface. The possibility may exist in respect to the persistence of some osteoarthritic induced features following morin administration not due to defect in morin per se, but they may be aggravated or be maintained by the concomitant trauma to the joint caused by the sustained use of the TMJ following arthritis induction.

\section{REFERENCES}

1. Liu F,Steinkeler A. Epidemiology, diagnosis, and treatment of temporomandibular disorders. Dent Clin North Am. 2013 Jul;57(3):465-79. doi:10.1016/j.cden.2013.04.006

2. Boyan BD, Tosi LL, Coutts RD, Enoka RM, HartDA, Nicolella DP, et al. Addressing the gaps: sex differences in osteoarthritis of the knee. Biol Sex Differ.2013 Feb 4;4(1):4. doi: 10.1186/2042-6410-4-4

3. TanakaE, Detamore MS, Mercuri LG. Degenerative disorders of the temporomandibular joint: etiology, diagnosis, and treatment. J Dent Res. 2008;87(4):296-307.doi:10.1177/154405910808700406

4. Matsumoto R, loi H, Goto TK, Hara A, Nakata S, Nakasima A, et al. Relationship between the unilateral TMJ osteoarthritis/osteoarthrosis, mandibular asymmetry and the EMG activity of the masticatory muscles: a retrospective study. J Oral Rehabil. 2010;37(2):85-92. doi:10.1111/.j:1365-2842.2009.02026.x

5. Krisjane Z,Urtane I,Krumina G,Neimane L, Ragovskal. The prevalence of TMJ osteoarthritis in asymptomatic patients with dentofacial deformities: a cone-beam CT study. Int J Oral Maxillofac Surg.2012;41(6):690-5. doi:10.1016/j. ijom.2012.03.006.

6. Wang XD, Zhang JN, Gan YH, Zhou YH. Current understanding of pathogenesis and treatment of TMJ osteoarthritis. JDentRes. 2015;94(5):666-73. doi:10.1177/0022034515574770

7. Kuyinu EL, Narayanan G, Nair LS, Laurencin CT. Animal models of osteoarthritis: classification, update, and measurement of outcomes. J Orthop Surg Res. 2016; 11:19. doi:10.1186/s13018-016-0346-5

8. Miyamoto S, Nakamura J, Ohtori S, OritaS, Omae T, Nakajima T, etal. Intraarticular injection of mono-iodoacetate induces osteoarthritis of the hip in rats. BMC Musculoskelet Disord. 2016 Mar; 18;17:132. doi:10.1186/s12891-016-0985-z

9. Pitcher T, Sousa-Valente J, Malcangio M. The Monoiodoacetate Model of Osteoarthritis Pain in the Mouse. J Vis Exp. 2016 May;(111):53746. doi:10.3791/53746.
10. Guingamp C, Gegout-PottieP,Philippe L, Terlain B, Netter P, GilletP.Monoiodoacetate-induced experimental osteoarthritis: a dose-response study of loss of mobility, morphology, and biochemistry. Arthritis Rheum. 1997;40(9):1670-9. doi:10.1002/art:1780400917.

11. Guzman RE, Evans MG, Bove S, Morenko B, Kilgore K. Mono-iodoacetateinduced histologic changes in subchondral bone and articular cartilage of rat femorotibial joints: an animal model of osteoarthritis. Toxicol Pathol. 2003;31(6):619-24. doi:10.1080/01926230390241800

12. Gutiérrez RM, Mitchell S, Solis RV. Psidium guajava: a review of its traditional uses, phytochemistry and pharmacology. JEthnopharmacol. 2008;117(1):1-27. doi:10.1016/j.jep.2008.01.025

13. Yue M,Zeng N, Xia Y,WeiZ, Dai Y.Morin exerts anti-arthritic effects by attenuating synovial angiogenesis via activation of peroxisome proliferator activated receptor-y. Mol Nutr Food Res. 2018;62(21):e1800202. doi:10.1002/ mnfr.201800202.

14. Chen WP,Hu PF, Bao JP,Wu LD. Morin exerts anti-osteoarthritic properties: an in vitro and in vivo study. Exp Biol Med. 2012;237:380-6. doi:10.1258/ ebm.2011.011271

15. Pufe T, Harde V, Petersen W, Goldring MB, Tillmann B, Mentlein R. Vascular endothelial growth factor (VEGF) induces matrix metalloproteinase expression in immortalized chondrocytes. J Pathol. 2004;202(3):367-74. doi:10.1002/ path.1527

16. Pritzker KPH, Gay S, Jimenez SA, Ostergaard K, Pelletier JP, Revell PA, et al. Osteoarthritis cartilage histopathology: grading and staging. Osteoarthritis Cartilage.2006;14(1):13-29. doi:10.1016/j.joca.2005.07.014

17. Wang XD, Kou XX, He DQ, Zeng MM, Meng Z, Bi RY, etal. Progression of cartilage degradation, bone resorption and pain in rat temporomandibular joint osteoarthritis induced by injection of iodoacetate. PLOS One.2012; 7(9):e45036. doi: 10.1371/journal.pone.0045036

18. Zeng N, Tong B, Zhang X, Dou Y, Wu X, Xia Y, etal. Antiarthritis Effect of Morin is Associated with Inhibition of Synovial Angiogensis. Drug Dev Res. 2015; 76(8):463-73. doi: 10.1002/ddr.21282

19. Walter JB, Hamilton MC, Israel MS. Principles of pathology for dental students. 3rd ed. Edinburgh:Churchill Livingstone; 1990. p. 464-5.

20. Wang XD, Kou XX, Meng Z, Bi RY, Liu Y, Zhang JN, etal. Estrogen aggravates iodoacetate-induced temporomandibular joint osteoarthritis. J Dent Res. 2013 Oct:92(10):918-24. doi: 10.1177/0022034513501323

21. Heijink A, Gomoll AH, Madry H, Drobni M, Filardo G, Espregueira-Mendes J, et al. Biomechanical considerations in the pathogenesis of osteoarthritis of the knee. Knee Surg Sports Traumatol Arthrosc. 2012 Mar;20(3):423-35. doi:10.1007/s00167-011-1818-0

22. Janusz MJ, Hookfin EB, Heitmeyer SA, Woessner JF, Freemont AJ, Hoyland JA, etal. Moderation of iodoacetate-induced experimental osteoarthritis in rats by matrix metalloproteinase inhibitors. Osteoarthritis Cartilage. 2001 Nov; 9(8): 751-60. doi:10.1053/joca.2001.0472

23. Dong Y,Wu G,Zhu T, Chen H, Zhu Y,Zhu G, et al. VEGF promotes cartilage angiogenesis by phospho-ERK $1 / 2$ activation of $D \| 4$ signaling in temporomandibular joint osteoarthritis caused by chronic sleep disturbance in Wistar rats. Oncotarget. 2017 Mar; 8 (11):17849-61. doi: 10.18632/ oncotarget.14874

24. Caselli A, Cirri P,Santi A, Paoli P.Morin: a promising natural drug. Curr Med Chem;2016 Jan;23(8):774-91. doi: 10.2174/0929867323666160106150821

\footnotetext{
Abdelrahman Mohamed Galal Abdelhameed (Corresponding address)

Al-Azhar University, $6^{\text {th }}$ District, Nasr City, Cairo, Egypt

Faculty of Dental Medicine- Boys

E-mail: dentist_amg@yahoo.com
}

Date submitted: 2019 Sep 11

Accept submission: 2020 May 15 